\title{
"Fluid" shift on chest radiography: Bochdalek hernia
}

\author{
Eun Joo Lee MD PhD, Sang Yeub Lee MD PhD
}

Previously published at www.cmaj.ca
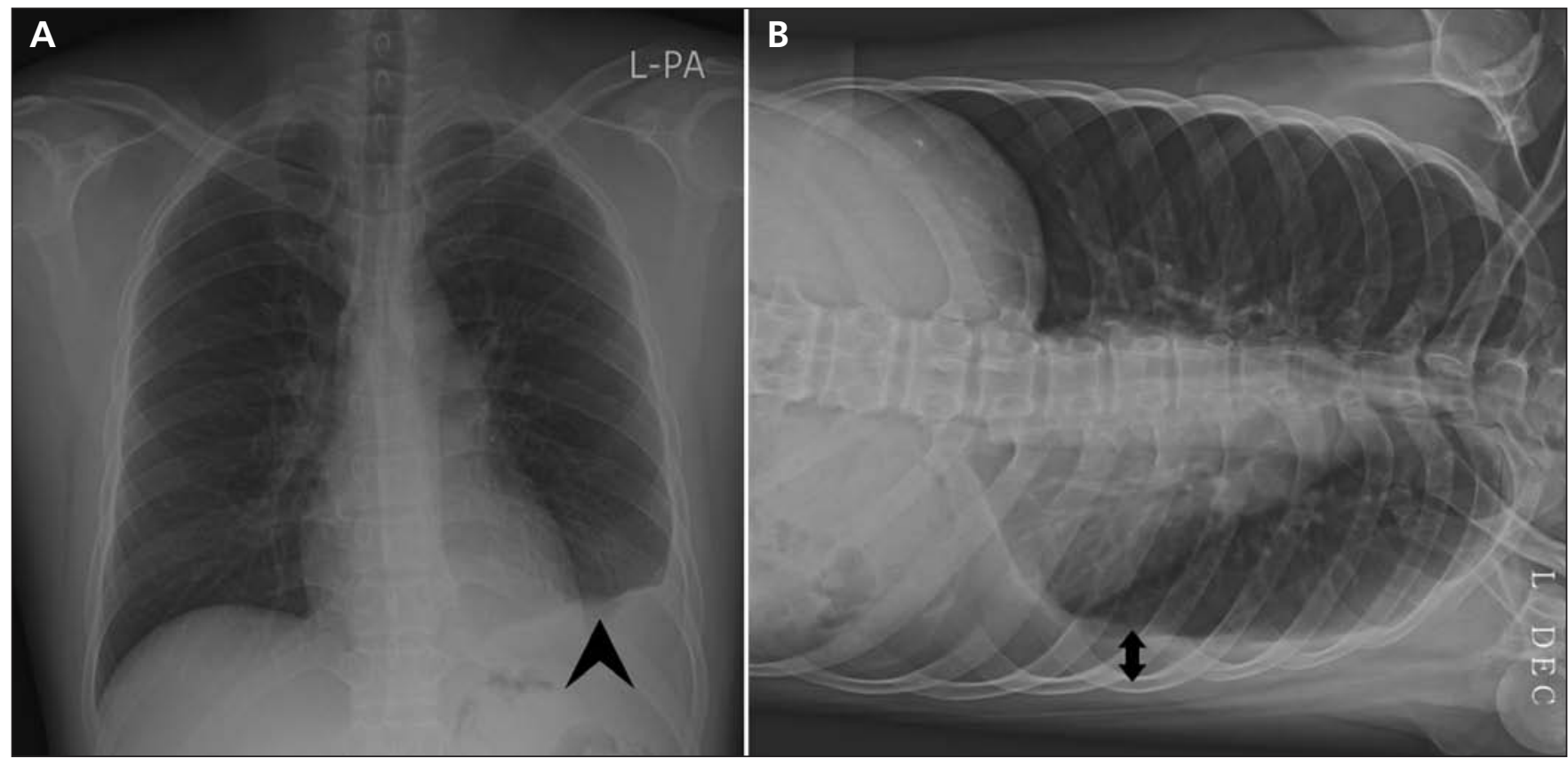

Figure 1: Chest radiographs in a 36-year-old man showing (left) blunting of the costophrenic angle (arrowhead) and (right) more than $1 \mathrm{~cm}$ of shifting opacity on the left lateral decubitus view (arrow).

A 36-year-old healthy man presented with a suspicious pleural effusion on the left side that had been found on a pre-employment chest radiograph. He denied having any respiratory symptoms, and there was no history of trauma. On examination, he had decreased breath sounds and tactile fremitus on the left side. A posteroanterior chest radiograph showed blunting of the left costophrenic angle (Figure 1A), with more than $1 \mathrm{~cm}$ of shifting opacity seen on the lateral decubitus radiograph, consistent with free fluid (Figure 1B). Diagnostic thoracentesis failed to produce fluid.

A computed tomography scan of the chest showed a prominent peritoneal fat herniation through a left posterolateral diaphragmatic defect, with no evidence of pleural fluid

From the Division of Respiratory and Critical Care Medicine, Department of Internal Medicine, Korea University Anam Hospital, Korea University College of Medicine, Seoul, Korea

CMAJ 2010. DOI:10.1503/cmaj.091323 collection (Figure 2). The patient refused further management and has remained symptom free.

A Bochdalek hernia, resulting from inadequate closure of the posterolateral pleuroperitoneal membrane, is the most common congenital diaphragmatic hernia, with an incidence of 1:2000 to 1:5000 live births. Congenital diaphragmatic hernias are usually found in neonates (approximately $10 \%$ of all reported cases occur in adults) and are associated with cardiac malformations and neural tube defects in up to $57 \%$ of patients. ${ }^{1,2}$ Chromosomal abnormalities, including trisomy 18 or trisomy 21 , have been described in $10 \%$ to $20 \%$ of all cases. Defects occur more frequently on the left side $(78 \%)$ than on the right side of the diaphragm, and abdominal contents, including stomach, bowel loops, liver, spleen or fat tissues, can be displaced into the thoracic cavity. ${ }^{3,4}$ Peritoneal fat, especially omental fat, tends to be mobile and can look like fluid on lateral decubitus chest radiographs. 
Congenital hernias in neonates can be asymptomatic and can result in death secondary to respiratory insufficiency. In contrast, most congenital diaphragmatic hernias in adults are

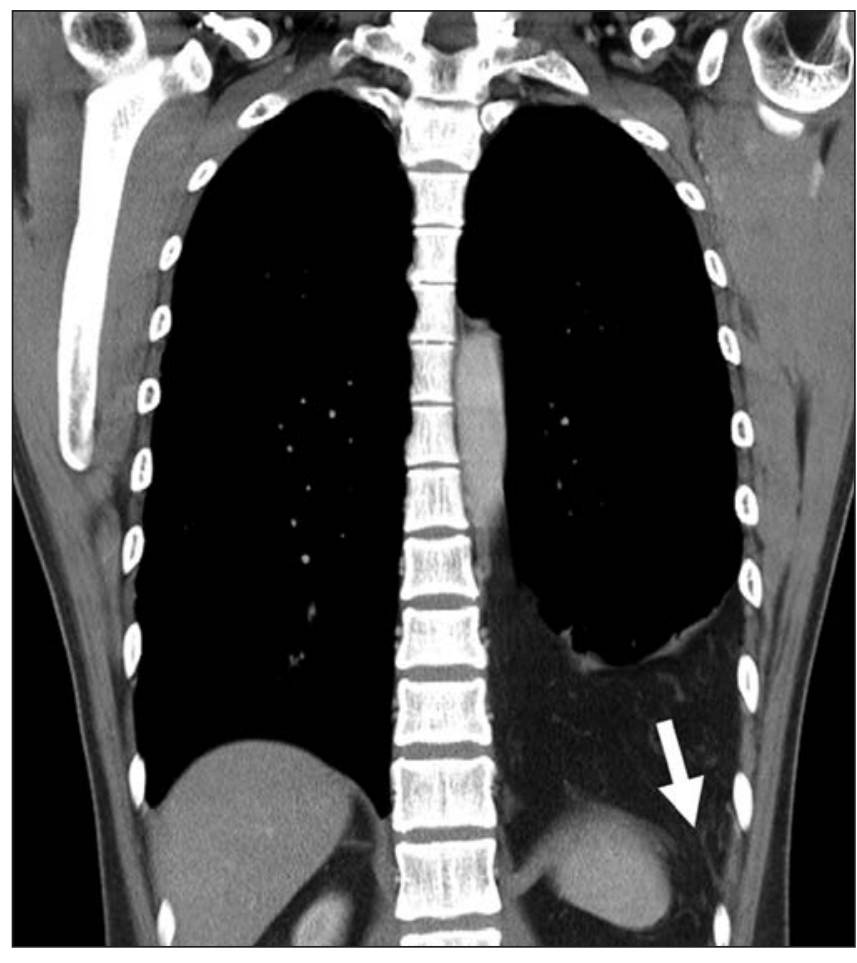

Figure 2: Computed tomography scan (coronal section) of the chest in a 36-year-old man showing a prominent peritoneal fat herniation through a left posterolateral diaphragmatic defect (arrow), with no evidence of pleural fluid collection. clinically silent. In $73 \%$ of adults, the hernia involves only omentum or fat. When symptoms do occur, they are relatively nonspecific and include chest or abdominal pain. ${ }^{5}$ Bochdalek hernia can be misdiagnosed as pleural effusion, pneumonia, pneumothorax, lung cysts, mediastinal tumour and atelectasis.

This article has been peer reviewed.

Competing interests: None declared.

\section{REFERENCES}

1. Zaleska-Dorobisz U, Baglaj M, Sokolowska B, et al. Late presenting diaphragmatic hernia: clinical and diagnostic aspects. Med Sci Monit 2007;13(Suppl 1):137-46.

2. Megremis SD, Segkos N, Gavridakis G, et al. Sonographic appearance of a latediagnosed left bochdalek hernia in a middle-aged woman: case report and review of the literature. J Clin Ultrasound 2005:33:412-7.

3. Yang W, Carmichael SL, Harris JA, et al. Epidemiologic characteristics of congenital diaphragmatic hernia among 2.5 million California births, 1989-1997. Birth Defects Res A Clin Mol Teratol 2006;76:170-4.

4. Gaxiola A, Varon J, Valladolid G. Congenital diaphragmatic hernia: an overview of the etiology and current management. Acta Paediatr 2009;98:621-7.

5. Mullins ME, Stein J, Saini SS, et al. Prevalence of incidental Bochdalek's hernia in a large adult population. AJR Am J Roentgenol 2001;177:363-6.

Clinical images are chosen because they are particularly intriguing, classic or dramatic. Submissions of clear, appropriately labelled high-resolution images must be accompanied by a figure caption and the patient's written consent for publication. A brief explanation (300 words maximum) of the educational significance of the images with minimal references is required. 